\title{
SAFE AND PRAGMATIC USE OF SODIUM-GLUCOSE CO-TRANSPORTER 2 (SGLT 2) INHIBITORS: MEDICATION COUNSELLING
}

\author{
Kalra S1*, Aamir AH², Amin MF³, Bajaj S4, Bulugahapitiya U5, Das AK ${ }^{6}$, Ghosh S7, Gunatilake S5, Mahar SA ${ }^{8}$, \\ Qureshi $N^{9}$, Raza SA ${ }^{10}$, Shrestha $D^{11}$, Somasundaram ${ }^{12}$, Sumanatilleke $\mathbf{M}^{13}$, Wijesinghe $\mathbf{A}^{12}$
}

\begin{abstract}
${ }^{1}$ Department of Endocrinology, Bharti Hospital, Karnal, India, ${ }^{2}$ Department of Endocrinology \& Metabolic diseases, Post Graduate Medical Institute, Hayatabad Medical Complex, Peshawar, Pakistan, ${ }^{3}$ Department of Endocrinology, BIRDEM, Dhaka, Bangladesh, ${ }^{4}$ Department of Medicine, MLN Medical College, Allahabad, India, ${ }^{5}$ Department of Endocrinology, Colombo South Teaching Hospital, Colombo, Sri Lanka, ${ }^{6}$ Department of Medicine, Pondicherry Institute of Medical Sciences, Puducherry, India, ${ }^{7}$ Department of Endocrinology, IGPGMR, Kolkata, India, ${ }^{8}$ Department of Medicine, National Institute of Cardiovascular Diseases, Karachi, Pakistan, ${ }^{9}$ Department of Endocrinology \& Diabetes, Asgar Ali Hospital, Dhaka, Bangladesh, ${ }^{10}$ Department of Medicine, Shaukat Khanum Cancer Hospital and Research Centre, Lahore, Pakistan, ${ }^{11}$ Department of Endocrinology, Norvic Hospital, Kathmandu, Nepal, ${ }^{12}$ Department of Endocrinology, National Hospital of Sri Lanka, Sri Lanka, ${ }^{13}$ Department of Endocrinology, Teaching Hospital Karapitiya, Galle, Sri Lanka.

*Corresponding author
\end{abstract}

\section{INTRODUCTION}

Diabetes management is a complex process and optimal therapeutic outcomes are achieved with patientcentered multi-disciplinary care (1). This includes non-pharmacological and pharmacological interventions and also the counselling. Diabetes counselling is a vast concept, which covers many aspects of diabetes care, including medication counselling, and this is distinct from diabetes education (2).

\section{MEDICATION AND COUNSELLING}

Medication counselling is essential to ensure the correct usage of medical products and this is especially true in the treatment of chronic disease such as diabetes (3). Medication counselling includes the information delivered related to the possible benefits, the effects and side effect, the need for precautions and monitoring during that particular drug therapy. This is possible through a process of informed and shared decision making. In diabetes, some topics of counselling are common to all classes of glucoselowering drugs, while some are unique to specific classes or molecules (4).

\section{SODIUM GLUCOSE COTRANSPORTER-2 (SGLT2) INHIBITORS}

Sodium-glucose cotransporter-2 (SGLT2) inhibitors are a new class of glucose-lowering drugs, which have recently been introduced in South Asia. Canagliflozin (100 and $300 \mathrm{mg}$ ), dapagliflozin (5 and $10 \mathrm{mg}$ ) and empagliflozin (10 and $25 \mathrm{mg}$ ) are some of the SGLT2 inhibitors available in South Asian countries. These drugs have a unique mechanism of action and reduce plasma glucose by enhancing glycosuria. Their mode of action creates the potential for benefits and side effects this class of drugs. This highlights the importance of appropriate use of SGLT2 inhibitors and the classspecific medication counselling (5).

\section{CLASS SPECIFIC COUNSELLING}

Table 1 lists the various issues that are discussed with the patient while considering prescription of SGLT2 inhibitors. A fair description of the expected benefits and possible side effects, anticipated level of glucose lowering, weight loss, blood pressure control, metabolic effects, and improvement in vascular outcomes of the drug are mainly considered.

\section{WARNING SYMPTOMS AND PREVENTION}

SGLT2 inhibitor related counselling also covers discussion about the expected increase in urinary output, the occurrence of glycosuria, and increased risk of genital mycotic infections (6). If relevant, SGLT 2 inhibitor related medication counselling should extend to identification, prevention and management of possible adverse events. Mycotic infections, identified by pruritic genital lesions in both men and 


\section{Table 1: Medication Counselling}

\begin{tabular}{l} 
Explain potential benefits \\
Degree of glycaemic control \\
Degree of weight lowering \\
Degree of BP lowering \\
Explain expected effects \\
Increased urine output $350 \mathrm{~mL}$ \\
Explain possible side-effects \\
Genital tract infections \\
Urinary tract infections \\
Volume depletion \\
Drug-drug interactions \\
Explain caveats \\
Disregard urine sugar reports \\
Explain mode of administration \\
Once daily at same time every day \\
Before first meal (CANA) or at any time (DAPA, EMPA) \\
But preferably during day time \\
Fluid intake \\
Perineal hygiene \\
Anti-fungal therapy \\
Vitamin D \\
\hline Cxplain \\
Clinical \\
Laboratory \\
Blteration of sensorium \\
Breathlessness \\
Explain \\
Explain warning signals \\
\hline
\end{tabular}

women, can be avoided by maintaining perineal hygiene (6). Volume depletion can be prevented by ensuring adequate fluid intake, avoiding concomitant use of loop diuretics and reassessing use of other diuretics (5).

The warning signals for diabetic ketoacidosis (DKA), including symptoms such as breathlessness, abdominal pain and altered sensorium must be explained to patients and their caregivers. This is especially important when SGLT2 inhibitors are prescribed in "high risk" situations, where DKA has been known to occur. These include fluid/carbohydrate restriction, acute mdical/surgical illness, and insulinopenic diabetes (7).

\section{POSOLOGY}

The cost, mode, frequency and timing of administration of the drug, as well as possible drug-drug interactions should be shared with patients prior to prescription. While canagliflozin should be taken before the first meal of the day, dapagliflozin and empagliflozin may be administered at any time, at the same time of the day. All drugs are administered as a single daily dose (8). During a period of fasting, such as Ramadan, it is prudent to advise to take the drug with iftar (i.e., at the time of breaking the fast).

\section{DRUG INTERACTIONS}

Significant drug-drug interactions must be noted by the physicians while initiating SGLT2 inhibitor therapy. The patient should be instructed to report any change in concomitant medication, even if advised by other physicians. It is noteworthy that there are few relevant drug interactions with SGLT2 inhibitor therapy.

\section{SUMMARY}

Understanding of the basic and clinical pharmacology of SGLT2 inhibitors, coupled with an appreciation of the patient's lifestyle, needs and priorities allow for the appropriate use of these drugs. Their utility is optimized if medication counselling is done as described above. This sharing of information, if done through a patient-centered dialogue (9), prevents avoidable adverse events, minimizes side effects, and maximizes therapeutic gain.

\section{ACKNOWLEDGEMENT}

This perspective is written by the South Asian Federation of Endocrine Societies (SAFES) working group, which met in Kathmandu, Nepal on 23 and 24 July 2016, to achieve consensus on the safe and pragmatic use of SGLT2 inhibitors in South Asia.

\section{REFERENCES}

1. Inzucchi SE, Bergenstal RM, Buse JB, Diamant M, Ferrannini E, Nauck $M$ et al. Management of hyperglycaemia in type 2 diabetes: A patient-centered approach. Position statement of the American diabetes association (ADA) and the European Association for the study of diabetes (EASD). Diabetologia. 2012; 55: 1577-1596.

2. Haas L, Maryniuk M, Beck J, Cox CE, Duker P, Edwards L et al. National standards for diabetes self-management education and support. Diabetes Care. 2013; 36: S100108. 
3. Halkoaho A, Kangasniemi M, Niinimäki S, Pietilä AM. Type 2 diabetes patients' perceptions about counselling elicited by interview: Is it time for a more health-oriented approach? European Diabetes Nursing. 2014; 11: 13-18.

4. Kalra S, Kalra B. Counselling patients for GLP-1 analogue therapy: Comparing GLP-1 analogue with insulin counselling. North American Journal of Medical Sciences. 2012; 4: 638-640.

5. Kalra S, Baruah MP, Sahay R. Medication counselling with sodium glucose transporter 2 inhibitor therapy. Indian Journal of Endocrinology and Metabolism. 2014; 18: 597-599.

6. Geerlings S, Fonseca V, Castro-Diaz D, List J, Parikh S. Genital and urinary tract infections in diabetes: impact of pharmacologically-induced glucosuria. Diabetes rese-arch and clinical practice. 2014; 103(3): 373-381.

7. Singh AK. Sodium-glucose co-transporter-2 inhibitors and euglycemic ketoacidosis: Wisdom of hindsight. Indian Journal of Endocrinology and Metabolism. 2015; 19: 722-730.

8. Kalra S. Sodium glucose cotransporter-2 (SGLT2) inhibitors: A review of their basic and clinical pharmacology. Diabetes Therapy. 2014; 5(2): 355-366.

9. Kalra S, Bantwal G, John M. The ADAEASD patientcentered guidelines for management of hyperglycemia: Are they patientcentered enough? Journal of Social Health and Diabetes. 2013; 1: 41-43. 